\title{
GESTAÇÃO POR SUBSTITUIÇÃO: DIREITO AO PLANEJAMENTO FAMILIAR VERSUS A AUTODETERMINAÇÃO CORPORAL
}

\section{Edenilza Gobbo* Elaine Julliane Chielle**}

Resumo: Este artigo analisa a colisão de dois direitos fundamentais que decorrem da Resolução n. ${ }^{\circ}$ 2.168/2017, que regulamenta a gestação por substituição. Para a realização da gestação por substituição é requisito documento com a expressa aprovação do cônjuge ou companheiro da cedente temporária casada ou convivente. Essa exigência garante ao cônjuge ou companheiro o exercício do direito ao planejamento familiar, o qual acaba colidindo com o direito à autodeterminação corporal da cedente temporária de útero. Busca-se resolver a presente problemática através das técnicas de ponderação, seguindo três passos propostos por Alexy.

Palavras-chave: Direitos Fundamentais; Planejamento Familiar; Autodeterminação Corporal; Gestação Por Substituição; Resolução n. ${ }^{\circ}$ 2.168/2017.

\section{REPLACEMENT MANAGEMENT: THE RIGHT TO FAMILY PLANNING VERSUS BODY SELF-DETERMINATION}

\begin{abstract}
This article analyzes the collision of two fundamental rights arising from Resolution No. 2,168 / 2017, which regulates the gestation by substitution. In order to perform gestation by substitution, a document with the express approval of the spouse or partner of the surrogacy one, married or cohabiting, is required. This requirement guarantees the spouse or partner the exercise of the right to family planning, which ends up colliding with the right to selfdetermination of the surrogate mother. We try to solve the present problem through the weighting techniques, following three steps proposed by Alexy.
\end{abstract}

Keywords: Fundamental Rights; Family planning; Body Self-Determination; Gestation By Substitution; Resolution nº ${ }^{\circ}$ 2.168/2017.

\footnotetext{
* É Mestre em Direito pela Universidade Federal de Santa Catarina; professora titular do Curso de Direito da Universidade do Oeste de Santa Catarina além de atuar em Curso de Pós-Graduação e advogada Especialista em Direito Civil. Sua pesquisa concentra-se nas áreas de Direito de Família e Direito da Criança e do adolescente. Atua na área do Direito das Famílias, Sucessões, Processo Civil, Criança e Adolescente e o Estatuto da Pessoa com Deficiência. E-mail: edenilza.gobbo@unoesc.edu.br

${ }^{* *}$ Mestra pelo Programa de Mestrado Acadêmico em Direito da Universidade do Oeste de Santa Catarina (2016), que possui como área de concentração as Dimensões Materiais e Eficaciais dos Direitos Fundamentais. Especialista pelo Programa de Pós-Graduação em Direito Civil e Processual Civil pela Universidade do Oeste de Santa Catarina (2014). Especialista pelo Programa de Pós-Graduação em Direitos Fundamentais da Família, Criança e Adolescente (2018). Graduada em Direito pela Universidade do Oeste de Santa Catarina (2012). Docente na Universidade do Oeste de Santa Catarina, unidade de Xanxerê e advogada. Endereço postal: Rua Victor Konder, 770, ap. 104, centro, Xanxerê - SC, CEP 89820-000. E-mail: elaine.chielle@ unoesc.edu.br
}

Rev. de Biodireito e Direito dos Animais | e-ISSN: 2525-9695 | Porto Alegre | v. 4 | n. 2 | p. 59-79 | Jul/Dez. 2018 


\section{INTRODUÇÃO}

Com o propósito de suprir a necessidade humana de reprodução e consecução de projetos de parentalidade, surgiram os métodos de reprodução assistida, que surgem como alternativas para sanar as mais variadas espécies de deficiências no processo reprodutivo. Alguns exemplos de reprodução assistida que podem ser citados são a fertilização in vitro e a inseminação artificial, tornando possível a reprodução por pessoas que antes não tinham essa possibilidade.

Contudo, havia também pessoas impedidas não apenas de gerar gametas férteis, mas também de gestar a criança, é o caso de casais homoafetivos, homens solteiros e algumas mulheres que, em decorrência de contraindicações médicas, estão impossibilitadas de gestar. Para esses casos, a tecnologia biomédica apresentou a possibilidade de reprodução através da gestação realizada no útero de outrem, sendo denominada Gestação de Substituição, que ficou popularmente conhecida como "Barriga de Aluguel".

No Brasil, muito embora exista essa técnica de reprodução assistida, não existe até o presente momento tratamento expresso sobre o assunto em legislação federal, sendo que os aspectos dessa forma de reprodução são tratados através da Resolução do Conselho Federal de Medicina (CFM) n. ${ }^{\circ}$ 2.168/2017, que permite a prática segundo determinadas condições estabelecidas pelo próprio órgão.

Referida Resolução trata a gestação por substituição em tópico específico, trazendo no seu texto requisitos para a realização da reprodução assistida, como a aprovação do cônjuge ou companheiro, apresentada por escrito, se a cedente temporária do útero for casada ou conviver em união estável.

A exigência do documento com a aprovação do cônjuge ou companheiro da cedente temporária do útero tem por intuito assegurar o exercício do direito ao planejamento familiar do cônjuge ou companheiro da cedente temporária do útero, decorrente do princípio planejamento familiar com raízes no art. $226, \S 7^{\circ}$, da Constituição Federal, o qual dispõe que o planejamento familiar é livre decisão do casal, fundado nos princípios da dignidade da pessoa humana e da paternidade responsável, sendo, portanto, um direito fundamental.

Por outro lado, contudo, há o direito à autodeterminação corporal da mulher cedente do útero, que é um direito decorrente da autonomia privada, da dignidade da pessoa humana e 
de um direito geral de liberdade, como forma de a própria cedente poder decidir livremente sobre aspectos pessoais e relativos ao seu corpo, também tido como um direito fundamental.

Dessa forma, percebe-se que a Resolução do Conselho Federal de Medicina (CFM) n. ${ }^{\circ}$ 2.168/2017 ao exigir a aprovação expressa do cônjuge ou companheiro da cedente de útero temporário para a realização do procedimento da gestação por substituição, acaba por suscitar a colisão entre dois direitos fundamentais.

O que se busca é apresentar uma solução à colisão desses direitos fundamentais, verificando qual deve prevalecer em um caso concreto utilizando-se a técnica da ponderação e a proporcionalidade de acordo com três passos sugeridos pelo filósofo Robert Alexy.

Para alcançar os objetivos aqui propostos, o presente artigo é construído em três capítulos, quais sejam: no primeiro é analisada a Resolução n. ${ }^{\circ}$ 2.168/2017 do CFM; no segundo capítulo é realizada a análise sobre a autodeterminação corporal, trazendo considerações e a contextualização, assim como apontamentos sobre a visão da teoria de Jean L. Cohen; e um terceiro capítulo, em que se busca realizar o sopesamento da colisão desses dois direitos fundamentais, utilizando a técnica da ponderação através de três passos propostos por Alexy.

Por fim, a justificativa da escolha deste tema para o desenvolvimento deste estudo, encontra-se na importância em analisar a colisão de dois direitos fundamentais, e principalmente em chegar a uma conclusão a respeito de qual direito deve prevalecer frente a um caso concreto de tentativa de gestação por substituição em que a cedente já tenha tomado a decisão pela realização do procedimento, mas o cônjuge ou convivente não forneça a autorização expressa para que referido procedimento possa ser realizado.

$\mathrm{O}$ presente estudo se desenvolve, portanto, mediante a pesquisa bibliográfica e documental, com busca por artigos, doutrinas, documentários, relatórios, notícias, leis nacionais e consultas a documentos eletrônicos, para que, com base na teoria preexistente do direito à autodeterminação corporal como um novo aspecto do direito à privacidade de Cohen, se analise se esse direito prevalece na colisão com outro direito fundamental, mais precisamente ao com relação ao direito ao planejamento familiar, tutelado pela Resolução n. ${ }^{\circ}$ 2.168/2017 do CFM. 


\section{A PRESERVAÇÃO AO DIREITO FUNDAMENTAL DO PLANEJAMENTO FAMILIAR NA GESTAÇÃO POR SUBSTITUIÇÃO}

A gestação por substituição, de acordo com Mariana Oliveira de Sá (2014), pode ser definida como uma técnica de reprodução humana artificial realizada com a participação de um terceiro (mãe substituta ou mãe de aluguel), que cede o útero, para o casal que, em decorrência de uma impossibilidade biológica para conceber um filho, possa vir a tê-lo, de forma diferente da convencional. Ou seja, a gestação ocorre no útero de uma terceira pessoa, chamada de cedente temporária do útero.

$\mathrm{O}$ ato da cedente temporária pode ser descrito até mesmo como um ato altruísta ou solidário, pois ocorre a cessão temporária do próprio útero e do próprio corpo em benefício de um casal (ou mesmo alguém sem companheiro ou cônjuge) que busque a realização da parentalidade, mas que por questões biológicas não conseguem alcançar esse desejo.

A gestação por substituição, de acordo com Gama (2008), pode ocorrer em três ocasiões. A primeira ocasião é aquela em que a maternidade de substituição (nomenclatura equivalente à gestação por substituição) ocorre através de um embrião resultante de óvulo e de espermatozoide do casal, com a implantação no corpo de outra mulher.

A segunda modalidade é aquela em que a maternidade por substituição envolve óvulo e gravidez da mulher que empresta seu corpo para gestar o embrião, comprometendo-se a entregar a criança ao casal solicitante (GAMA, 2008). O sêmen utilizado na procriação é do marido que resolveu, juntamente com sua esposa, efetivar o projeto parental.

Por fim, a terceira modalidade de maternidade por substituição consiste naquela em que embrião é formado a partir da união de óvulo da própria mulher cedente do útero e de espermatozoide de terceiro doador, ou seja, o casal que pretende ter o filho não contribui com material fecundante (GAMA, 2008).

A gestação por substituição não possui legislação federal específica que trate sobre o tema, possuindo sua regulamentação através da Resolução do Conselho Federal de Medicina (CFM) n. ${ }^{\circ}$ 2.168/2017, que adota as normas éticas para a utilização das técnicas de reprodução assistida, dentre elas, a da gestação por substituição, de acordo com condições estabelecidas pelo próprio órgão.

Referida Resolução autoriza a realização da gestação por substituição desde que exista um problema médico que impeça ou contraindique a gestação na doadora genética, ou quando

Rev. de Biodireito e Direito dos Animais | e-ISSN: 2525-9695 | Porto Alegre | v. 4 | n. 2 | p. 59 - 79 | Jul/Dez. 2018 
o casal não possua condições de gestar por se tratar de união homoafetiva, ou ainda por tratarse de pessoa solteira.

Importante destacar ainda que a Resolução requer que a cedente temporária do útero pertença à família de um dos parceiros, com parentesco consanguíneo até o quarto grau, ou seja, até a prima. Caso a cedente não se encaixe nesse requisito de parentesco, para que o procedimento seja realizado é necessária autorização do Conselho Regional de Medicina.

A Resolução dispõe ainda que a cessão temporária do útero não poderá ter caráter lucrativo ou comercial, então por mais que a gestação por substituição tenha ficado conhecida popularmente como "barriga de aluguel", é vedado o objetivo de obter vantagem onerosa através do procedimento.

Referida Resolução traz também requisitos necessários para a realização da gestação por substituição, consistindo em documentos que devem constar no prontuário da paciente. Os documentos exigidos são: a) Termo de Consentimento Livre e Esclarecido, devidamente assinado pelo (s) paciente (s) e pela cedente temporária do útero, contendo informações sobre aspectos biopsicossociais e riscos envolvidos no ciclo gravídico-puerperal, bem como aspectos legais da filiação; b) um relatório médico com a descrição do perfil psicológico, atestando adequação clínica e emocional de todos os envolvidos; c) Termo de Compromisso realizado entre o (s) paciente (s) e a cedente temporária do útero, estabelecendo expressamente a questão da filiação da criança; d) um compromisso fornecido pelo (s) paciente (s) de tratamento e acompanhamento médico, inclusive por equipes multidisciplinares, se necessário, à mãe que cederá temporariamente o útero, até o puerpério; e) o compromisso do registro civil da criança pelos pacientes (pai, mãe ou pais genéticos), devendo esta documentação ser providenciada durante a gravidez; e f) a aprovação do cônjuge ou companheiro, apresentada por escrito, se a cedente temporária do útero for casada ou conviver em união estável.

Analisando tudo o que inclui e afeta uma gestação, mesmo que por substituição, parece até diminuto chamar a mulher que se dispõe a tal procedimento como mera cedente temporária do útero, pois em verdade a cedente temporária não dispõe apenas de seu útero, mas de seu próprio corpo, com reflexos psicológicos, de imagem e identidade.

Tendo a cedente temporária se apresentado voluntariamente para o procedimento e assinado o Termo de Compromisso, os profissionais responsáveis pela realização do procedimento para a gestação por substituição já possuem a anuência da mulher para ceder temporariamente seu útero, podendo tomar todas as medidas necessárias para a reprodução, 
mas além do consentimento da mulher que cede seu próprio corpo para a realização da gestação por substituição, se ela for casada ou conviver em união estável, o Conselho Federal de Medicina, através da Resolução n. ${ }^{\circ}$ 2.168/2017, requer também a anuência do marido ou companheiro da cedente, anuência esta que deve ser apresentada por escrita, pois assim faz prova no prontuário da cedente.

A essa altura, pode surgir o questionamento de qual o objetivo da exigência da aprovação expressa do marido ou companheiro da cedente para a realização do procedimento de gestação por substituição, já que quem está se submetendo ao procedimento é a própria cedente. Pois bem, uma resposta plausível a esse questionamento trata-se da tutela ao direito ao planejamento familiar, que muito embora seja um direito exercido comumente pelo casal, é direito garantido a cada indivíduo, e nesse caso, especificamente ao marido ou companheiro da cedente temporária.

Para a conceituação sobre o direito ao planejamento familiar, utilizando definição de Chagas e Lemos (2013), as autoras descrevem que esse termo, da forma como foi introduzido no ordenamento jurídico brasileiro, está limitado às ações de controle de fecundidade (contracepção) e de estímulo a ela (possibilidade de conceber). Referidas autoras descrevem que o planejamento familiar encerra mais do que a ideia de limitação do número de filhos, que vai além até mesmo dos aspectos procriativos, pois deve abranger todo o planejamento necessário ao pleno desenvolvimento e amparo da família, tais como moradia, alimentação, lazer, educação, vestuário, etc. (CHAGAS; LEMOS, 2013).

O planejamento familiar diz respeito aos direitos reprodutivos, entre os quais se insere o direito à procriação, e ambos estão intimamente ligados à autodeterminação reprodutiva.

Com relação à autodeterminação reprodutiva Chagas e Lemos (2013) descrevem que não inclui apenas a decisão sobre o número de filhos e o momento de gerá-los, inclui também o direito de não ser discriminado (a) se a decisão fosse no sentido da não-procriação.

O direito ao planejamento familiar encontra previsão na Constituição Federal de 1988, que no seu artigo $6^{\circ}$ dispões expressamente que: "São direitos sociais a educação, a saúde, o trabalho, a moradia, o lazer, a segurança, a previdência social, a proteção à maternidade e à infância, a assistência aos desamparados, na forma desta Constituição". Desse dispositivo conclui-se que a maternidade como um direito social, inserido no título referente aos direitos e garantias fundamentais.

Rev. de Biodireito e Direito dos Animais | e-ISSN: 2525-9695 | Porto Alegre | v. 4 | n. 2 | p. 59 - 79 | Jul/Dez. 2018 
Também na Constituição Federal de 1988, no artigo 226, §7º há dispositivo que fundamenta o planejamento familiar nos princípios da dignidade da pessoa humana e da paternidade responsável, e ainda que o planejamento familiar seja uma decisão que deve ser tomada livremente pelo casal, sendo competência do Estado "propiciar recursos educacionais e científicos para o exercício desse direito, vedada qualquer forma coercitiva por parte de instituições oficiais ou privadas".

Sobre a caracterização do direito ao planejamento familiar como um direito fundamental, Chagas e Lemos (2013), afirmam que os direitos reprodutivos vão além da simples capacidade de decidir sobre a fertilidade e o momento de exercê-la, pois contorna também o questionamento sobre a maternidade como projeto de vida obrigatório para as mulheres e a paternidade como parte necessária da vida dos homens.

Ainda, no que diz respeito aos direitos sexuais e reprodutivos, pode-se afirmar que reconhecem o direito das pessoas de organizar sua vida reprodutiva e de buscar os cuidados oferecidos pela ciência para obter a solução e restabelecimento da saúde sexual e reprodutiva (CHAGAS; LEMOS apud BRAUNER, 2013).

O direito do ser humano de constituir família e ter filhos é reconhecido em textos jurídicos internacionais como um direito a ser exercido sem intervenções arbitrárias (como exemplo a Declaração Universal dos Direitos Humanos em seu art. 12), podendo ser entendido como um direito personalíssimo, indisponível e inalienável, devendo ser protegido pelo Estado e suas instituições (CHAGAS; LEMOS apud BRAUNER, 2013).

Desse modo, inegável que o direito ao planejamento familiar seja caracterizado como um direito fundamental de gerar ou de não gerar filhos, conforme conclusão das autoras Chagas e Lemos (2013).

Para tanto, mediante tal afirmação tão bem formulada por referidas autoras, retomando a o disposto na Resolução n. ${ }^{\circ}$ 2.168/2017, referente à necessidade da manifestação do cônjuge ou companheiro da cedente de útero sobre sua anuência sobre a realização de referido procedimento, conclui-se que seja a mais pura forma de garantia do exercício do direito fundamental ao planejamento familiar, pois o que se oportuniza que o cônjuge ou companheiro autorize ou não a realização do procedimento com base no seu interesse e planos sobre o aumento da família ou não.

A formação de uma família e os direitos reprodutivos são garantidos tanto ao casal como ao indivíduo isolado, pois para formar uma família não necessariamente será através do 
casamento ou da união estável, como outrora no Direito Romano ou Direito Canônico, pois como já descrito nesse artigo, existem as famílias monoparentais, formadas por apenas um dos genitores e o (os) filho (s). Isso significa que o indivíduo que não possui um cônjuge ou companheiro não está privado do direito ao planejamento familiar, mas, por outro lado, quando já existe uma estrutura familiar através do casamento ou da união estável, o planejamento familiar é um direito exercido de forma conjunta.

É justamente nesse sentido que a Resolução n. ${ }^{\circ}$ 2.168/2017 exige que, além do ato permissivo da mulher cedente temporária do útero para a realização da gestação por substituição, seja apresentado documento com aprovação do cônjuge ou companheiro para a realização do procedimento.

Desse modo, resta constatado que a Resolução n. ${ }^{\circ}$ 2.168/2017 tutela o direito fundamental ao planejamento familiar do cônjuge ou companheiro da cedente temporária do útero.

\section{A AUTODETERMINAÇÃO CORPORAL DA CEDENTE TEMPORÁRIA DO ÚTERO PARA A REALIZAÇÃO DA GESTAÇÃO POR SUBSTITUIÇÃO}

A autodeterminação corporal, uma das ramificações da autodeterminação, decorre da autonomia e do direito à liberdade, possuindo estreito liame com a privacidade e com os direitos individuais, se apresenta como essencial para que o indivíduo construa sua própria identidade.

Usufruir de um direito à privacidade, segundo Cohen (2012), garante uma autonomia decisória a respeito de certos assuntos pessoais. Além disso, significa que a pessoa não deve ser obrigada a revelar os motivos pessoais para escolhas éticas ou a aceitar, como próprias, as razões ou julgamentos manifestados pelo grupo onde esteja inserida (COHEN, 2012). Em suma, trata-se de uma liberação da obrigação de justificar as próprias ações.

Também há que se adiantar sobre a autonomia privada ser manifestação da liberdade, o que faz com que seja considerada como um dos meios de realização da dignidade da pessoa humana em situações existenciais (MEIRELES, 2009).

Nesse sentido Pona (2015), descreve sobre a autonomia privada não ser mais apenas simples reconhecimento da vontade dos indivíduos para que eles criem obrigações, mas em ser também um poder normativo relegado aos particulares de forma que os mesmos regulem a própria vida de acordo com seus interesses, não podendo aqui o Estado intervir.

Rev. de Biodireito e Direito dos Animais | e-ISSN: 2525-9695 | Porto Alegre | v. 4 | n. 2 | p. 59 - 79 | Jul/Dez. 2018 
Com base no exposto acima, surge então a ideia da autodeterminação empregada ao indivíduo, tida como forma de o próprio indivíduo se autogovernar quanto às decisões de cunho estritamente pessoais, de realizar suas decisões e escolhas de acordo com sua vontade como forma da busca de um bem-estar, de uma realização e concretização de direitos existenciais. Essa forma de autodeterminação ainda é algo recente e de conceito pouco divulgado.

A autodeterminação, conforme descrita por Barroso e Martel (2012), se trata de uma capacidade que decorre da dignidade como autonomia, sendo "o direito de decidir os rumos da própria vida e de desenvolver livremente a própria personalidade".

A autonomia corporal é entendida por Lima e Freitas (2013) como a capacidade de autodeterminação do indivíduo com relação ao seu corpo, e se encontra inserida na seara da existencialidade ou extrapatrimonialidade, isto é, espécie do gênero da autonomia existencial. É autonomia concedida ao indivíduo com o objetivo assegurar tutela integral do corpo humano para constituir um sujeito singular, o qual, através de um amplo domínio sobre sua integridade psicofísica, poderá construir por si próprio um corpo que lhe permita chegar ao seu ideal de vida digna. Os autores salientam que não é uma ótica que deixa de lado a concepção dualista do corpo cingida em corpo e espírito, pelo contrário, é concepção unitária, restando afastada a dissociação entre o corpo e a própria pessoa (LIMA; FREITAS, 2013). E ao “constituir-se como um conceito promocional da livre determinação corporal, ela impede que sejam impostos limites abstratos a tal direito" (LIMA; FREITAS, 2013).

Nesse aspecto também Cohen (2012) ensina que "nós somos nossos corpos", explicando que nosso corpo, a interpretação que temos de nosso corpo, a interpretação simbólica do próprio corpo e o sentimento de controle sobre ele são centrais para um sentido de individualidade, de identidade e dignidade pessoal. Assim "nossas individualidades, nossas identidades, estão intrinsecamente implicadas em nossos corpos e no que fazemos deles - pois nossos corpos são o nosso modo de ser no mundo." (COHEN, 2012).

O corpo é visto como um dos territórios centrais de si, e um sentimento de controle sobre o próprio corpo é crucial para que se mantenha a percepção íntegra de si, e também para a capacidade de interagir com outros. A autoconfiança do indivíduo é firmada no sentimento de que ele possa dispor livremente de seu próprio corpo, que pode coordenar suas funções e regular o acesso a ele (COHEN, 2012).

Através de tal perspectiva, ao analisar a decisão referente à cessão temporária do útero para a realização do procedimento para a gestação por substituição, conclui-se que é uma 
decisão personalíssima, referente ao corpo da cedente temporária, e nesse aspecto, trata-se de decisão a ser tomada única e exclusivamente pela própria cedente, sem interferências indevidas de terceiros, da sociedade ou do Estado.

Utilizando a concepção aqui apresentada da autodeterminação corporal como um direito à autonomia privada e decisória sobre aspectos do próprio corpo, compete à cedente temporária decidir livremente sobre a realização ou não da gestação por ser decisão que define resultados suportados somente por ela, pois é o seu útero, o seu corpo e da sua mente que estará dispondo.

Ao decidir sobre uma gestação, mesmo uma gestação de substituição, em que o filho a ser concebido não será um filho seu, mas sim de outrem a quem a cedente tem interesse em auxiliar na concretização da maternidade e/ou paternidade, inúmeros são os reflexos que essa decisão acarretará para a própria cedente. Alguns desses reflexos podem ser descritos como: alterações físicas, hormonais e psicológicas, a submissão de exames, procedimentos médicos e acompanhamento durante muitos meses, finalizando na realização de um procedimento cirúrgico para a realização do parto, além de alterações referentes à sua imagem e sua identidade, pois passa a ser vista e identificada na sociedade e no meio em que convive, como gestante e como mãe.

Dessa forma, a efetividade de um direito à autodeterminação corporal a essa cedente temporária com relação à realização da gestação por substituição de modo livre, sem apresentar justificavas pela sua decisão e principalmente sem intervenções indevidas de terceiros, trata-se da concretização de um sentimento de controle sobre o seu próprio corpo, que é o cerne mais básico para o sentido de individualidade e para a sua identidade e dignidade pessoal.

Nesse ponto, retomando a tutela ao planejamento familiar em favor do cônjuge ou companheiro da cedente que é garantido pela Resolução n. ${ }^{\circ}$ 2.168/2017 do CFM, que traz no seu bojo o requisito de que para a realização do procedimento seja apresentado no prontuário da paciente documento escrito com autorização do cônjuge ou companheiro da cedente a autorização para a gestação por substituição, o que ocorre é uma interferência na decisão da cedente, pois não basta que esta apresente sua anuência através do Termo de Consentimento Livre e Esclarecido, é necessária a autorização de terceiro.

Esse requisito apresentado pelo CFM através de referida Resolução, por mais que tenha o desígnio de tutelar o direito fundamental ao planejamento familiar, acaba, por outro 
lado, acarretando na lesão a outro direito fundamental, que é justamente o da autodeterminação corporal da cedente temporária.

Impor que o procedimento da gestação por substituição precise, além da anuência da cedente, a autorização do cônjuge ou companheiro para que o procedimento seja realizado, é condicionar e até sobrepor a decisão já tomada pela cedente à deliberação de terceiro.

Interferir na decisão da cedente sobre a realização significa interferir no sentimento de controle sobre o próprio corpo da cedente, é retirar dela o poder de gerir seu próprio corpo, de ter sua individualidade integralizada, é reduzir um direito geral de liberdade e, o mais importante, interferir na sua identidade e dignidade pessoal.

\section{PLANEJAMENTO FAMILIAR VERSUS AUTODETERMINAÇÃO CORPORAL}

Considerando que nenhum direito fundamental é absoluto e que em casos concretos é muito comum que ocorra a colisão entre direitos fundamentais, torna-se necessária a adoção de métodos aptos a resolver esses conflitos com o menor prejuízo e restrição possível a cada um dos bens envolvidos, mediante fundamentação jurídica plausível.

Nesse sentido Silveira (2013) relata que nos casos concretos em que ocorra a colisão entre direitos de igual hierarquia, é grande importância uma técnica capaz de solucionar a querela posta ao Estado-juiz, por meio de critérios que, ainda que com certa carga de subjetividade, são informados por outros em que contenha uma objetividade em que o jurisdicionado pode questionar e fiscalizar o equacionamento da tensão pelo intérprete responsável pela resolução da lide.

Quando o intérprete realiza a ponderação de bens em dado caso de conflito entre direitos fundamentais, ele estabelece uma precedência de um sobre o outro, ou seja, é atribuído um peso maior a um deles e é possível estabelecer uma fundamentação para o resultado, de modo que se elimina o irracionalismo subjetivo e passa a ter um racionalismo objetivo (BARROS, 1996).

Esta concepção está correlacionada ao princípio da unidade da Constituição, o qual procura, dentro de uma visão global da Constituição, tornar harmônicas as tensões que porventura possam existir entre normas colidentes (SILVEIRA, 2013).

A ponderação de interesses exsurge quando, em um caso concreto, dois ou mais princípios constitucionais acabam por colidir, competindo a um intérprete realizar a 
interpretação dos cânones envolvidos, com a finalidade de verificar se eles efetivamente se confrontam na resolução do caso ou se é possível harmonizá-los (SILVEIRA, 2013). Caso não seja possível harmonizá-las, passará o intérprete a uma segunda fase de análise, qual seja, a ponderação de interesses.

Com relação ao princípio da proporcionalidade, antes de qualquer coisa, mostra-se imperioso diferenciar duas espécies de normas jurídicas: as regras e os princípios.

De acordo com ensinamentos e Alexy (2008) anto os princípios quanto às regras servem como fundamentos para a resolução de casos concretos, o que os diferencia são suas aplicações: as regras são normas que podem ser cumpridas ou não, já os princípios são normas que ordenam que algo seja realizado na maior medida possível dentro das possibilidades jurídicas e fáticas.

No caso de conflito entre duas regras (utilizando os meios clássicos de interpretação, com a aplicação dos critérios cronológico, hierárquico e de especialidade para a resolução do caso concreto), haverá a aplicação apenas de uma delas, pois uma será válida e outra não, já no caso de colisão entre princípios, através da ponderação, será aplicado aquele que tiver maior peso ou importância naquele caso concreto. Desse modo, diferentemente do que as regras, no caso de colisão de princípios não há a exclusão de um deles.

Nesse sentido, imperioso trazer à baila os ensinamentos de Alexy (2008), que adverte que a solução para a colisão de princípios deve ser realizada de forma diversa, pois na colisão de dois princípios, apenas um prevalece, mas isso não significa que o princípio cedente deva ser declarado inválido, nem que nele deverá ser introduzida uma cláusula de exceção. O que ocorre é que um dos princípios tem precedência em face do outro sob determinadas condições, sendo possível que mediante outras condições a questão da precedência poderia ser resolvida de forma oposta (ALEXY, 2008). Isso significa que em cada caso concreto os princípios têm pesos diferentes, e que os princípios com o maior peso (em cada caso) têm precedência (ALEXY, 2008). A justificativa para tal deve-se ao fato de que, enquanto nos conflitos entre regras ocorrem na dimensão da validade, nas colisões entre princípios ocorrem na dimensão do peso (ALEXY, 2008).

Desse modo, ocorrendo conflitos jurídicos decorrentes da colisão de normas fundamentais, tanto na interpretação das normas do Código como na aplicação ou interpretação do ordenamento jurídico em vigor, pode o juiz solucionar o caso utilizando o princípio da proporcionalidade, inclusive é o que dispõe art. $8^{\circ}$ do Código de Processo Civil, que traz o 
seguinte dispositivo: “Ao aplicar o ordenamento jurídico, o juiz atenderá aos fins sociais e às exigências do bem comum, resguardando e promovendo a dignidade da pessoa humana e observando a proporcionalidade, a razoabilidade, a legalidade, a publicidade e a eficiência".

A utilização do princípio da proporcionalidade para solução de conflitos de normas fundamentais também é prevista no mesmo código no art. 489, parágrafo $2^{\circ}$, que exige que "no caso de colisão entre normas, o juiz deve justificar o objeto e os critérios gerais da ponderação efetuada, enunciando as razões que autorizam a interferência na norma afastada e as premissas fáticas que fundamentam a conclusão".

Nesse contexto, aplicando as técnicas da ponderação e o princípio da proporcionalidade para a resolução de conflitos de direitos fundamentais, passa-se a analisar a solução proposta à problemática do presente artigo, que consiste na verificação de possível divergência de direitos em um caso concreto.

O caso hipotético consiste na possibilidade de uma mulher casada ou que conviva em união estável, que esteja disposta a ceder temporariamente seu útero em favor de alguém que, em decorrência de alguma impossibilidade para gestar, necessite do procedimento da gestação por substituição para conseguir realizar o desejo de ter filhos. Todos os requisitos da Resolução n. 2.168/2017 do CFM já devidamente preenchidos, com exceção apenas a autorização expressa do cônjuge ou companheiro da cedente para a realização de referido procedimento, documento este que não foi cedido porque o cônjuge ou companheiro não concorda com o procedimento motivado por projetos que ele possua com a sua esposa sobre ter (ou não) filhos naquele mesmo período.

Em decorrência da não autorização expressa do cônjuge ou companheiro da cedente temporária do útero, apesar de ela mesma já ter decidido pela realização do procedimento para gestação temporária, como já descrito, referido procedimento não poderá ser realizado pela falta de uma autorização elencada como necessária. Desse modo, com base nessa situação, surge o questionamento: ocorrendo divergência de vontades, e consequentemente a colisão de direitos entre a autodeterminação corporal da cedente temporária do útero e o direito ao planejamento familiar do cônjuge ou companheiro, qual direito deve prevalecer?

Mediante todo o exposto no presente artigo, restou evidenciada que a Resolução n. ${ }^{\circ}$ 2.168/2017 do CFM apresenta uma tutela ao direito fundamental ao planejamento familiar ao cônjuge ou convivente da cedente temporária de útero. Por outro lado, a decisão da cedente temporária de útero trata-se de uma decisão que deve ser exercida exclusivamente pela própria 
cedente, por trata-se de uma decisão sobre seu próprio corpo, uma decisão de cunho íntimo e personalíssimo, devendo ser realizada pela própria cedente, sem interferências de terceiros ou do Estado, como forma de exercício de um direito fundamental à autodeterminação corporal.

Para tanto, empregando a lei da ponderação em harmonia com as afirmações de Robert Alexy (2008), é necessária a decomposição em três passos. Num primeiro passo deve ser comprovado o grau do não cumprimento ou prejuízo de um princípio. Por segundo deve ocorrer a comprovação da importância do cumprimento do princípio em sentido contrário. Finalmente, no terceiro passo deve ser comprovado se a importância do cumprimento do princípio em sentido contrário justifica o prejuízo ou não cumprimento do outro.

Aplicando esses passos ao problema em questão, que pode ser visualizado num caso concreto em que uma mulher casada ou que mantenha união estável decida por realizar o procedimento de gestação por substituição, mas o seu marido ou companheiro se contrapõe ao procedimento, motivado, por exemplo, pelo interesse talvez em ter filhos com a cedente naquele período, não fornecendo a autorização por escrito. Nessa situação ocorre a colisão entre os dois direitos fundamentais em questão: o direito à autodeterminação corporal, decorrente de um direito à autonomia privada e a um direito geral de liberdade, e por outro lado o direito ao planejamento familiar, que igualmente decorre de um direito à autonomia privada, de um direito um direito geral à liberdade.

Com relação ao primeiro passo proposto por Alexy, referente ao grau do não cumprimento ou prejuízo de um princípio, de início verifica-se para o exercício do planejamento familiar por parte do cônjuge através da autorização para a realização do procedimento para a gestação por substituição, caso o marido não conceda a autorização, ocorrerá a total privação do exercício da autodeterminação corporal por parte da cedente temporário do útero, pois sem esse requisito ou o procedimento não é realizado, ou a cedente carece de substituição da autorização nas vias judiciais, o que significa que novamente dependerá da autorização de terceiro (do Estado) para poder efetivar uma decisão que já manifestou.

Com relação aos prejuízos que a não autorização por parte do cônjuge pode causar, inicialmente se constata na frustração para o casal que deseja a realização dos projetos familiares, que por si só já significa um prejuízo muito grande, pois pode ser que esse casal não encontre outra pessoa ligada à família que esteja disposta a realizar o procedimento, o que implicaria em sérias dificuldades na realização do projeto familiar por eles almejado. 
Ademais, o prejuízo direto quem sofre é à própria cedente, pois deixa de exercer um empoderamento sobre seu próprio corpo, fica impedida de concretizar um ato pelo qual já decidiu, ato este que significa uma realização pessoal, se analisada pelo fato de ser uma decisão altruísta com o objetivo de prestar auxílio às pessoas próximas a ela. Ao analisar a autodeterminação corporal de acordo com a concepção apresentada por Cohen, a não efetivação da autodeterminação corporal para a cedente temporária em decorrência da preponderância do planejamento familiar do marido, pode acarretar ainda em interferências na sua individualidade e na sua identidade, visto que estas construções estão intrinsecamente implicadas em nossos corpos e no que fazemos deles.

Há prejuízos também relativos à autoconfiança da cedente, visto que o sentimento de autoconfiança é firmado no sentimento de poder dispor livremente de seu corpo, na coordenação das funções e regulamentação sobre o acesso a ele. Por fim, tudo isso pode influir ainda na capacidade da cedente em interagir com os outros, de participar ativamente numa sociedade, pois somente um indivíduo que tenha individualidade e identidade, e, por conseguinte, que sejam seguros, autoconfiantes e realizados, são capazes de participar ativamente no meio em que se encontrem. Isso caracteriza um grau elevado de prejuízo.

Por outro lado, ao analisar o grau do não cumprimento ou prejuízo que com relação ao planejamento familiar ao marido ou companheiro da cedente, importante destacar que a efetivação da autodeterminação corporal da cedente não anula por completo o direito ao planejamento familiar, pois a decisão da cedente temporária sobre a gestação por substituição não significa que ela não tenha planejamentos com o próprio cônjuge ou companheiro, significa apenas que durante aquele período (de meses ou um ano, se considerar o período de recuperação pós parto), não serão concretizados os planejamentos que estes possuem.

Contudo, considerando os prejuízos que possíveis pela não concretização do planejamento familiar naquele momento, por certo que, da mesma forma, acarretaria em prejuízos de ordem pessoal ao cônjuge ou companheiro, pois o planejamento familiar trata de uma das maiores (se não a maior) realização possível ao ser humano independente de a decisão ser sobre gerar ou não gerar filhos. Acarreta também em prejuízos de ordem privada, considerando que uma decisão relativa a questões pessoais não pode ser exercida. Ademais, pode ser citado ainda que também acarreta um sentimento incapacidade e de incompletude.

Apesar de a efetivação do direito ao planejamento familiar do cônjuge ou companheiro não ocorrer (temporariamente) em decorrência do exercício da autodeterminação corporal da 
cedente, o dos prejuízos que de ordem pessoal que isso pode importar, ainda assim não superam os prejuízos pela supressão do direito à autodeterminação corporal da cedente.

Partindo para o segundo passo indicado por Alexy, referente à comprovação da importância do cumprimento do princípio em sentido contrário, basta realizar o primeiro passo em sentido contrário, ou seja, a efetivação da autodeterminação corporal por parte da cedente temporária resulta em: uma grande realização ao casal que possui projetos familiares e conta com o auxílio da cedente para alcançar essa realização, a cedente concretiza o sentimento de empoderamento sobre seu próprio corpo, o sentimento de domínio sobre ele e sobre as decisões sobre o rumo do seu corpo e de assuntos estritamente pessoais, se autoafirma, constrói sua autoconfiança, sua identidade e sua individualidade.

Por outro lado, se o direito ao planejamento familiar é concretizado, o marido ou cônjuge da cedente terá um sentimento de plenitude e potencializará sua autoconfiança, vez que pode exercer o direito de exercer uma decisão de cunho pessoal, referente a uma grande realização pessoal enquanto ser humano, podendo decidir tanto por ter filhos quanto por não ter filhos.

Nesse segundo ponto fica difícil a ponderação sobre qual dos direitos demonstram maior importância, pois ambos são de cunho individual e privado, o que inevitavelmente traz valores extremamente subjetivos, parecendo ser mais acertada a decisão de atribuir iguais valores à importância do cumprimento de cada um deles.

Por fim, com relação ao terceiro passo, é realizada a análise sobre a importância do cumprimento do princípio em sentido contrário, se justifica o prejuízo ou não cumprimento do outro. Novamente iniciando a análise através da autodeterminação corporal da cedente temporária, vale mencionar que ela já possui uma decisão com realização a realização da gestação por substituição, uma decisão que traz grandes repercussões, e que por conseguinte repercute em grandes resultados, tais como o sentimento de realização pessoal por auxiliar pessoas próximas na realização de um projeto familiar que, não fosse pela sua atuação, teria dificuldades em ser realizado, mas principalmente por dizer respeito à sua autoafirmação, a construção de sua identidade, ao sentimento de empoderamento sobre seu próprio corpo, de se ver livre para decidir sobre questões estritamente pessoais. Vale aqui citar um exemplo da realização de uma cirurgia plástica, tal como a cirurgia para colocação de próteses mamárias, cirurgia de nariz ou de "orelhas de abano", por certo que a pessoa já possui uma decisão quanto ao que deseja fazer com seu próprio corpo, e não poder concretizar essa decisão em decorrência 
da falta de autorização de outra acarreta numa frustração que, deixando de lado a questão estética, significa uma lacuna na autoconfiança da pessoa, o que acarreta em deficiências na formação da sua identidade e na sua individualidade.

Por outro, a se a autodeterminação corporal da cedente for efetiva, o seu marido ou cônjuge deixa de exercer o direito ao planejamento familiar, deixa de manifestar uma decisão e vontade crucial para a sua realização pessoal, para a realização dos projetos familiares que este possui, o que pode acarretar em diversos prejuízos de ordem sentimental e existencial.

Contudo, apesar de ambos os direitos serem de extrema importância, afinal são direitos fundamentais, deve prevalecer o direito à autodeterminação corporal em detrimento do planejamento familiar, isso porque, se for considerada a irreversibilidade dos danos que pode acarretar a prevalência deste, a autodeterminação corporal não poderá ser reafirmada em igual situação, já o direito ao planejamento familiar ainda pode ser exercido em outros momentos ou através de outros métodos.

Desse modo, mediante todo o exposto, muito embora não seja tarefa fácil a ponderação destes direitos fundamentais, a conclusão alcançada é que a autodeterminação corporal da cedente temporária merece prevalecer em detrimento ao planejamento familiar do cônjuge ou companheiro, principalmente pelo fato de a autodeterminação corporal dizer respeito às necessidades identitárias e constitutivas do próprio ser, e que se abaladas, podem ocasionar prejuízos irreversíveis, ao ponto que o planejamento familiar, que possui valor inestimável, ainda pode ser reversível através de outros métodos ou em outros momentos.

\section{CONSIDERAÇÕES FINAIS}

Levando em consideração estudo desenvolvido, o que se percebe é que a colisão entre direitos fundamentais pode ocorrer em casos concretos, e que mesmo através da aplicação da ponderação e não é tarefa fácil a resolução do caso em questão.

No presente caso foi realizada análise da colisão entre dois direitos fundamentais. Tratou-se especificamente da colisão de direitos decorrente da Resolução n. ${ }^{\circ}$ 2.168/2017 do CFM, que trata sobre s técnicas de reprodução assistida, dentre essas técnicas está a gestação por substituição.

Em análise à referida Resolução, é exigida a autorização do cônjuge ou convivente da cedente temporária do útero para que seja efetivado o procedimento. Desse modo, ficou 
evidente que a Resolução n. ${ }^{\circ}$ 2.168/2017 do CFM tutela o direito ao planejamento familiar com relação ao cônjuge ou companheiro da cedente temporária do útero.

O direito ao planejamento familiar consiste na autodeterminação reprodutiva, está diretamente ligado aos direitos reprodutivos e ao direito à procriação. Não estando limitado apenas à decisão sobre ter filhos, mas também sobre não ter filhos, decisão esta que deve ser garantida ao casal ou mesmo ao indivíduo que não possua parceiro.

Por outro lado, há o direito à autodeterminação corporal da cedente temporária do útero em poder decidir livremente sem interferências de terceiros sobre aspectos pessoais e relativos ao próprio corpo.

Ao analisar o direito à autodeterminação corporal, aderiu-se à teoria de Jean L. Cohen (2012), a qual trabalha a autonomia corporal através da autonomia decisória como um direito à privacidade, vista como necessária para a afirmação de identidades individuais e como respeito às decisões autônomas dos indivíduos sobre questões concernentes ao seu corpo e questões íntimas relevantes da sua identidade.

Surge então a problemática sobre qual desses dois direitos deve prevalecer, para o que foi utilizada a técnica da ponderação de acordo com os passos sugeridos por Robert Alexy, quais sejam: a comprovação do grau do não cumprimento ou prejuízo de um princípio; a comprovação da importância do cumprimento do princípio em sentido contrário; e a comprovação se a importância do cumprimento do princípio em sentido contrário justifica o prejuízo ou não cumprimento do outro.

Após a realização desses passos concluiu-se pela prevalência do direito à autodeterminação corporal da cedente temporária do útero, considerando principalmente o primeiro e o último passo, ou seja, a análise do prejuízo do não cumprimento e se é justificável ou não o prejuízo do não cumprimento do direito contrário.

Considerando que a ponderação de princípios visa sempre a aplicação de métodos aptos a resolver esses conflitos com o menor prejuízo e restrição possível a cada um dos bens envolvidos, conclui-se que a autodeterminação corporal da cedente temporária deve prevalecer no caso concreto de colisão com o planejamento familiar do seu cônjuge ou companheiro.

Além do mais, tecendo breves comentários sobre as batalhas das mulheres para alcançar direitos básicos, como exemplo o direito à igualdade de tratamento, direito ao trabalho e liberdade, e de tantas batalhas que ainda travam para tornar efetivos os direitos já conquistados e para alcançar tantos outros, não parece acertada a ideia de condicionar decisões de cunho 
estritamente pessoal, decisões que dizem respeito ao seu próprio corpo à autorização de terceiros para poder efetivar. Isso significaria um retrocesso aos direitos da autonomia já conquistados, coloca a mulher na condição existente na concepção de família existente no Direito Romano ou no Direito Canônico, ou seja, como submissa e dependente do marido, equiparada a mero objeto da propriedade ora do próprio pai, ora do marido, sem poder decidir o rumo da própria vida.

Por fim, conclui-se também que a liberdade para exercer autonomamente decisões sobre o próprio corpo é imprescindível para que o indivíduo estabeleça uma relação com seu próprio corpo, para que ele tenha o sentimento de poder e controle sobre seu próprio corpo. Com essa relação e esse sentimento, é possível a construção de uma autoconcepção, se reconhecerá como ser singular e formará a sua identidade.

\section{REFERÊNCIAS}

ALEXY, Robert. Teoria dos Direitos Fundamentais. São Paulo: Malheiros, 2008.

ARAÚJO, Luiz Alberto David; NUNES, Vidal Serrano Júnior. Curso de direito constitucional. 1. ed. ver. e atual. São Paulo: Saraiva, 2006.

BARROS, Suzana de Toledo. O Princípio da Proporcionalidade e o Controle de Constitucionalidade das Leis Restritivas de Direitos Fundamentais. 1. ed. Brasília: Brasília Jurídica, 1996.

BARROSO, Luís Roberto; Martel, Letícia de Campos Velho. A morte como ela é: Dignidade e autonomia individual no final da vida. Consultor jurídico, 2012. Disponível em: $<$ http://www.conjur.com.br/2012-jul-11/morte-ela-dignidade-autonomia-individual-finalvida>. Acesso em: 05 mai. 2016.

BRASIL. Constituição da República Federativa do Brasil. Disponível em < http://www.planalto.gov.br/ccivil_03/constituicao/constituicaocompilado.htm>. Acesso em 10 de mai. de 2018.

Lei $\mathbf{n}^{\mathbf{0}} \mathbf{9 . 2 6 3}$ de 12 de janeiro de 1996. Disponível em <

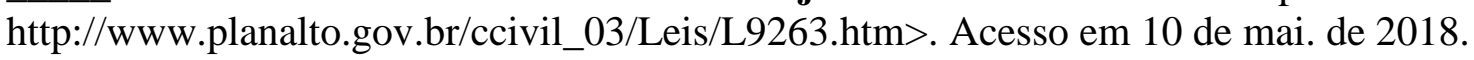

Lei $\mathbf{n}^{\circ} \mathbf{1 3 . 1 0 5}$ de 16 de março de 2015. Disponível em < http://www.planalto.gov.br/ccivil_03/_ato2015-2018/2015/lei/113105.htm>. Acesso em 10 de mai. de 2018. 
BITTAR, Carlos Alberto. Os Direitos da Personalidade. Rio de Janeiro: Forense, 1998.

CANTALI, Fernanda Borghetti. Direitos da Personalidade: disponibilidade relativa, autonomia privada e dignidade humana. Porto Alegre: Livraria do Advogado Editora, 2009.

CHAGAS, Márcia Correia de; LEMOS, Mariana Oliveira. O Direito ao planejamento familiar como direito humano fundamental autônomo e absoluto?. Disponível em: <http://www.publicadireito.com.br/artigos/?cod=39a1dafc5f8576b4>. Acesso em: 5 mai. 2018.

COHEN, Jean L. Repensando a privacidade: autonomia, identidade e a controvérsia sobre o aborto. Revista Brasileira de Ciência Política. Brasília, DF, n. 7, p.165-203, abr. 2012. Disponível em: < http://www.scielo.br/pdf/rbcpol/n7/a09n7.pdf>. Acesso em: 5 mai. 2018.

FARIAS, Cristiano Chaves de. ROSENVALD, Nelson. Direito das Famílias. $2^{\mathrm{a}}$ Ed. Rio de Janeiro: Editora Lumen Juris, 2010.

GAMA, Guilherme Calmon Nogueira da. Direito Civil - família. São Paulo: Atlas, 2008.

GONÇALVES, Carlos Roberto. Direito Civil Brasileiro: Direito de Família - $15^{\mathrm{a}}$ ed., São Paulo: Saraiva, 2018.

GOMES, Orlando. Direito de Família. Rio de Janeiro: Forense, 2000.

GOMES, Renata Raupp. A relevância da bioética na construção do novo paradigma da filiação na ordem jurídica nacional, In: LEITE, Eduardo de Oliveira (coord.). Grandes temas da atualidade: bioética e biodireito. Rio de Janeiro: Forense, 2004.

LIMA, Rodrigo; FREITAS, Silva de. Autonomia Privada Existencial e Paternalismo Jurídico: O caso da autonomia corporal. 2013. Disponível em: <http://www.pucrio.br/pibic/relatorio_resumo2013/relatorios_pdf/ccs/DIR/DIR-

Rodrigo\%20Lima\%20e\%20Silva\%20de\%20Freitas.pdf>. Acesso em: 06 mai. 2018.

MEIRELES, Rose Melo Venceslau. Autonomia Privada e Dignidade Humana. Rio de Janeiro: Renovar, 2009.

OLIVEIRA, Alexandre Miceli Alcântara de. Direito de autodeterminação sexual. São Paulo: Editora Juarez de Olivera, 2003.

PONA, Éverton Willian. Testamento vital e autonomia privada: fundamentos das diretivas antecipadas de vontade. Curitiba: Juruá, 2015.

; AMARAL, Ana Cláudia Corrêa Zuin Mattos do. Autonomia da vontade privada e testamento vital: a possibilidade de inclusão no ordenamento jurídico brasileiro. Revista do Direito Privado da UEL. n. 3. Disponível em: <http://www.uel.br/revistas/direitoprivado/artigos/Everton_e_Ana\%20Cl\%C3\%A1udia_Auto nomia_da_vontade_privada_e_testamento_vital.pdf>. Acesso em: 05 mai. 2016. 
RUSSO, José. As Sociedades Afetivas e Sua Evolução. Revista Brasileira de Direito de Família, Porto Alegre, v.7, n. 32, out - nov. 2005.

SÁ, Mariana Oliveira. A gestação por substituição: Da autonomia da vontade aos direitos do nascituro. Disponível em: < http://publicadireito.com.br/publicacao/ufsc/livro.php?gt=98>. Acesso em: 05 mai. 2016.

SANTOS, Natália Petersen Nascimento. Autodeterminação individual: Pode o sujeito dispor do próprio corpo ou da própria vida?. Conteúdo Jurídico, Brasília-DF: 26 fev. 2016. Disponível em: <http://www.conteudojuridico.com.br/?artigos\&ver $=2.55296 \&$ seo $=1>$. Acesso em: 05 mai. 2016 .

SILVEIRA, Vinicius Loureiro da Mota. Ponderação e proporcionalidade no direito brasileiro. $\quad$ Disponível

<http://www.egov.ufsc.br/portal/conteudo/pondera\%C3\%A7\%C3\%A3o-eem: proporcionalidadeno-direito-brasileiro>. Acesso em: 05 mai. 2018.

Saúde, Corpo e Autonomia Privada. Rio de Janeiro: Renovar, 2010. 